\title{
Strangulation of Penis: Two Cases Report \& Review
}

\author{
Snigdha Goyal ${ }^{*}$, Isha Saini' ${ }^{2}$, Sunder Goyal ${ }^{3}$ \\ ${ }^{1}$ Department of Pathology, Dr. RML Postgraduate Institute of Medical Sciences, New Delhi, India \\ ${ }^{2}$ Honorary Research Fellow, Kalpna Chawla Medical College, Karnal, Haryana, India \\ ${ }^{3}$ Department of Surgery, Kaplna Chawla Medical College, Karnal, Haryana, India \\ Email: ${ }^{\text {drgoyal4@gmail.com, ishasdoc@gmail.com, goyal.sunder@yahoo.in }}$
}

Received 2 July 2015; accepted 18 July 2015; published 24 July 2015

Copyright (C) 2015 by authors and OALib.

This work is licensed under the Creative Commons Attribution International License (CC BY).

http://creativecommons.org/licenses/by/4.0/

(c) (i) Open Access

\begin{abstract}
Various metallic and non-metallic objects are placed over the penis to increase sexual performance or because of sexual gratification. Hypersexuality can be cause of such bizarre behaviors. We present two cases of perversion due to hypersexual behavior. One patient used a hard plastic disposable cold drink bottle nozzle over his penis for masturbation which resulted in strangulation of the penis. In the $2^{\text {nd }}$ case, a constricting ring was used to prolong the erection which resulted in necrosis of penile skin. Both cases were managed successfully.
\end{abstract}

\section{Keywords}

Penile Strangulation, Plastic Bottle Nozzle, Metallic Objects, Sexual Gratification

Subject Areas: Surgery \& Surgical Specialties

\section{Introduction}

In 1755 the first case of penile strangulation has been reported in literature. Adults use foreign bodies on the penis for sexual gratification [1]. They mostly use rings, nuts, plastic bottles, wedding rings etc. for sexual gratification which may result in penile strangulation. Children may use rubber bands, threads or hair coils out of curiosity [2]-[4]. Metallic or non-metallic objects like beverage bottle are usually put on the penis by the patient himself for masturbation or by his female partner to prolong erection [5]-[8]. Constricting object compresses veins and lymphatic and results in penile edema and necrosis. As these patients cannot remove such constricting objects themselves, so they always seek medical advice. Due to a fear of social stigma, usually these patients seek medical advice quiet late and present with complications. Varieties of objects, cause of strangulation, degree of injury and treatment modalities are different for each patient [7]-[10]. Removal of these constricting ar-

"Corresponding author. 
ticles is usually demanding for treating surgeons. Depending on the type of constricting material, special equipment is essential for successful removal of the foreign bodies. We share our experience of managing penile strangulation in two patients: one with nozzle of a cut plastic bottle and another with metallic ring.

\section{Case Report}

\section{1. $1^{\text {st }}$ Case}

A 27-year-old male presented in the emergency with markedly swollen penis. He had placed a hard plastic bottle nozzle over his penis for masturbation. The bottle nozzle got stuck and constricted the base of the penis. On Examination there was a bottle nozzle around the base of penis. The distal penis and glans was swollen with ecchymosis of skin (Figure 1). Patient was not able to pass urine. There was no evidence of any skin ulceration. The distal penile sensations were slightly blurred. The bone cutter was used to cut bottle nozzle and the bottle neck was cut opened and removed after 15 minutes of struggle. There was only ecchymosis of the skin after removal of plastic bottle nozzle (Figure 2). Patient was catheterized. Penile edema subsided completely in a week and patient had an uneventful recovery. There was no erectile dysfunction or decreased urine flow till six months of follow up.

\section{2. $2^{\text {nd }}$ Case}

A 30 years old male presented with necrosis of penile skin as result of penile constriction due to a metallic ring. Metallic ring was placed at base of pen is to prolong the erection. On examination, there was necrosis of whole of penile skin (Figure 3). Patient was not able to pass urine. The distal penile sensations were blurred. Urethra

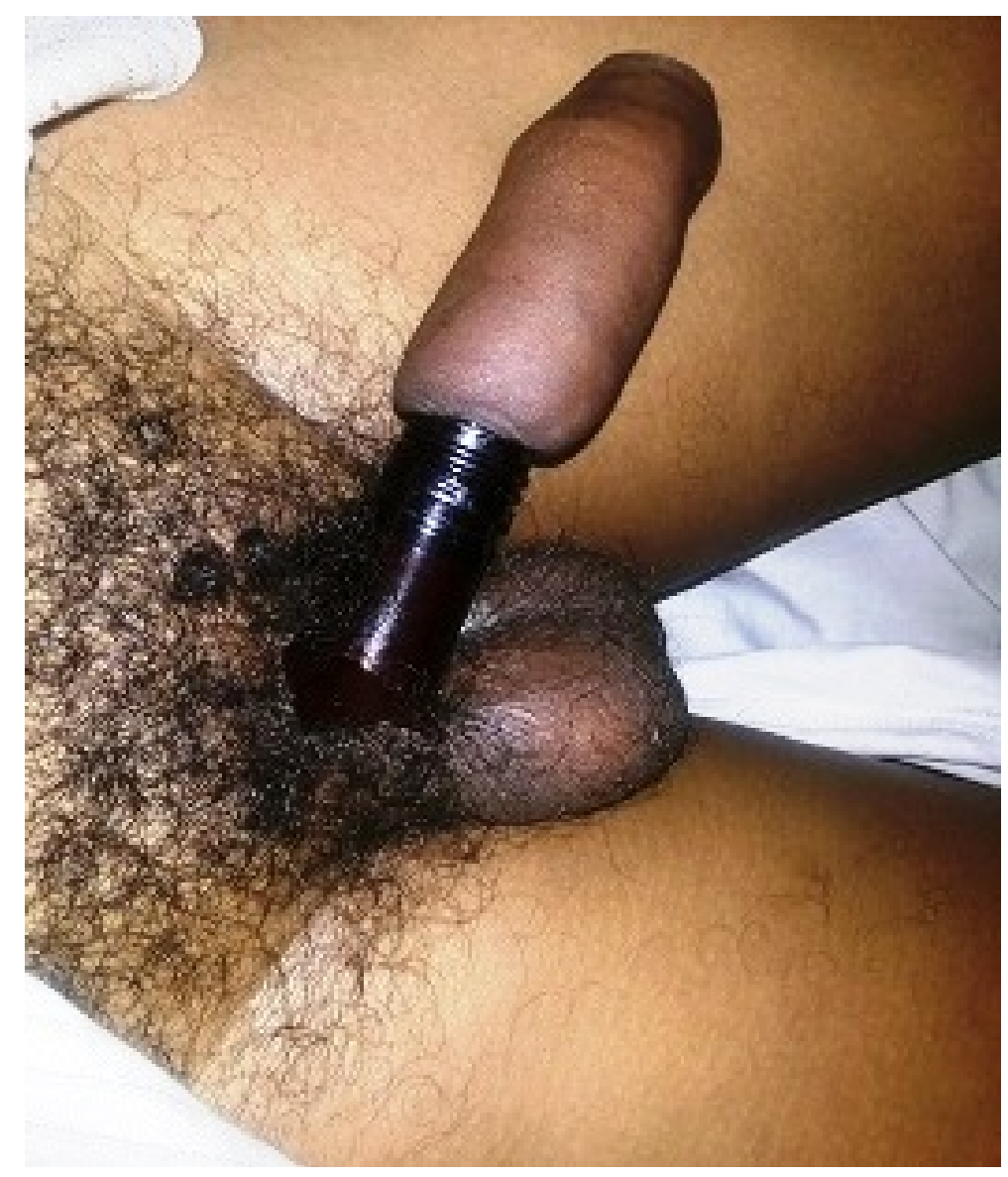

Figure 1. Showing strangulated penis with plastic bottle nozzle with ecchymosis. 


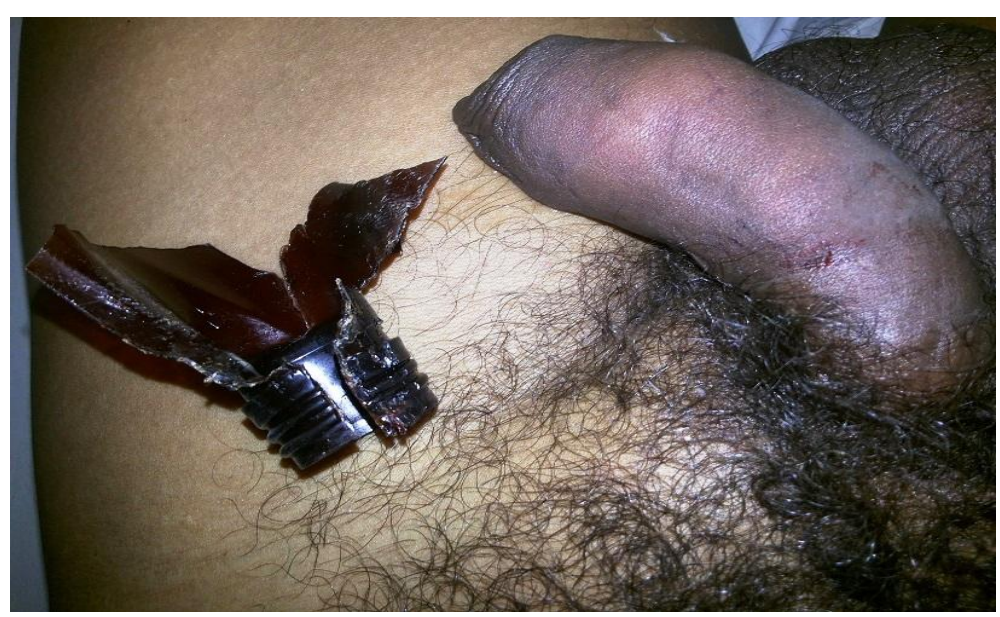

Figure 2. Ecchymosis of skin of penis after excision of nozze.

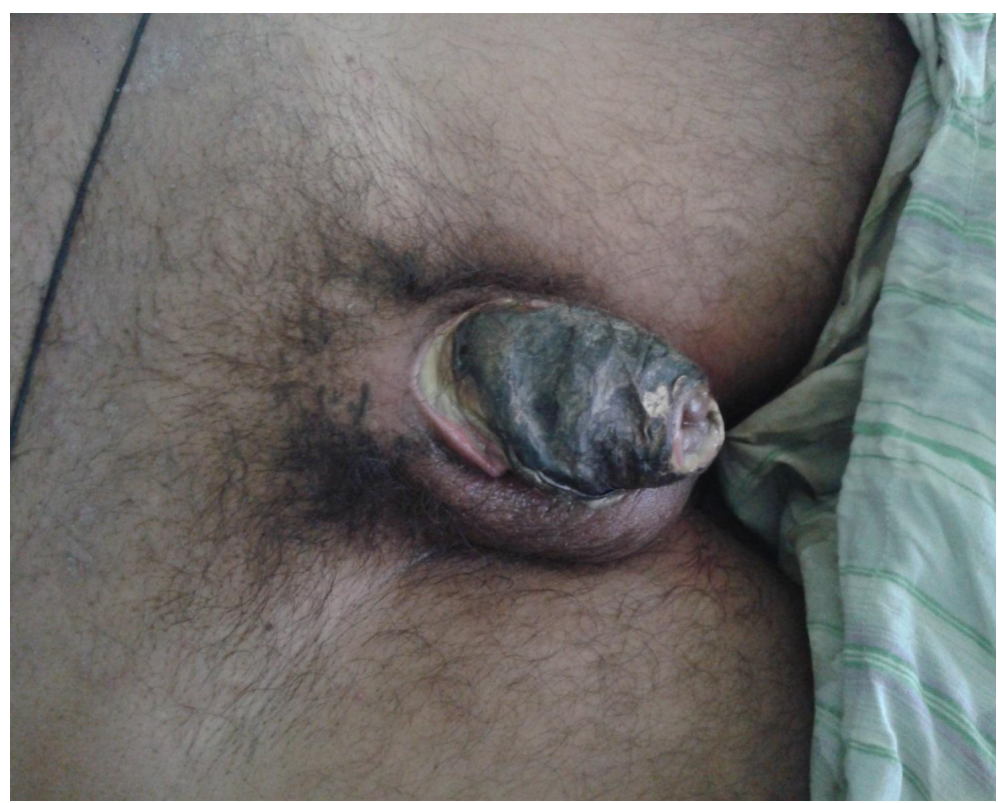

Figure 3. Showing necrosed skin of penis due ring around the penis.

was normal. The metallic ring was removed with combination of penile aspiration and String Technique. Catheterization was done. Necrosed skin was excised and split skin graft was put. Catheter was removed after two weeks. Patient passed urine freely. There was no erectile dysfunction. Postoperative period was uneventful. Patient was alright in follow up for 6 months period.

\section{Discussion}

Metallic or non-metallic objects like beverage bottle are usually put on the penis by the patient himself for masturbation or by his female partner to prolong erection [5]-[8]. These abnormal articles around penis may cause penile strangulation injuries. These injuries range from simple penile engorgement to ulceration, necrosis, urinary fistula or even gangrene.

Different causes of penile injuries are like strangulation injuries, zipper injuries, due to use of erection- inducing devices, sexual abuse, and torture. In some social culture, penis is wrapped deliberately with strangulating objects in an effort to protect against evil spirits or to treat urinary incontinence or nocturnal emissions [11]. Penile strangulation by metallic rings is most difficult to manage, as it may stop arterial supply, lymphatic flow 
and thus causes gangrene. Sometime it may result in amputation [12].

AL Bhat et al. (1999) graded these injuries as follows [6].

Grade I Edema of distal penis. No evidence of skin ulceration or urethral injury.

Grade II Injury to skin and constriction of corpus spongiosum but no evidence of urethral injury. Distal penile edema with decreased penile sensation.

Grade III Injury to skin and urethra but no urethral fistula. Loss of distal penile sensations.

Grade IV Complete division of corpus spongiosum leading to urethral fistula and constriction of corpus cavernosa with loss of distal penile sensations.

Grade V Gangrene, necrosis, or complete amputation of distal penis.

As these patients cannot remove such constricting objects themselves so, they always seek medical advice. Mostly these patients come with complications due to late presentation. The evaluation of penile strangulation can be done by local temperature, sensation, color, ability to void, distal pulsations and local tissue injury at the site of constriction. In case of absent pulsations the distal blood flow can be checked by Doppler flow meter or wood lamp examination after IV Fluroscein [13].

The choice of method for removal depends upon type, size, incarceration time, trauma grade, and availability of the equipment to remove the constricting object. Prompt diagnosis and early treatment are essential to avoid the potential complications of ischemic necrosis and auto amputation. Removal of such devices is usually challenging and often requires imagination and a multidisciplinary approach [14].

Treatment techniques for penile incarceration can generally be divided into four groups: the string technique and its variants, with and without aspiration of blood from the glans; aspiration techniques; cutting devices; and surgery [15]. In our first case, cutting device, bone cutter was used and in second case, the string technique was used.

After the removal of the object the urethra should be evaluated radiologically. If grade III-V injuries are found, urinary diversion should be done via suprapubic puncture. In grade I and II injuries, simple emptying of the bladder by urethral catheterization maybe required. But more severe cases may require suprapubic cystostomy, urethral reconstruction, degloving and skin grafting or sometimes amputation.

To our knowledge, our first case is the second report of a penile trap in a PET bottle nozzle and $3^{\text {rd }}$ case of penile strangulation with bottle nozzle. Rigidity of the material is extremely high, especially as these bottles are manufactured for recycling purpose.

Our $1^{\text {st }}$ case had grade I injury and $2^{\text {nd }}$ case had grade II injury. In both the cases constricting article were removed. In $2^{\text {nd }}$ case skin grafting was done. Both patients improved without any complication like impotence or stricture urethra.

Use of various abnormal articles around the penis for sexual gratification or due to perverted behavior may be sometime due to paraphilia. These patients should always undergo a psychosexual assessment. Hypersexuality can change sexual behaviors. The etiology of hypersexuality is multifaceted and engages a variety of physiological and psychological mechanisms. Malfunctioning of Frontal lobe can result in bizarre and hypersexual behavior [16]. The psychosexual assessment is essential to prevent such episodes of bizarre behavior in future.

\section{Conclusion}

Penile strangulation is a serious injury requiring urgent attention and intervention to prevent the complications. Aim should be restoration of blood supply and micturition with least discomfort to the patient. Removal of these constricting articles is usually demanding for treating surgeons as there are chances of injury to the penis of patient. Depending on the type of constricting material, special equipment is essential for successful removal of the foreign bodies. Long-term follow-up with micturating cysto-uretherogram (MCU) and uroflowmetery is necessary. Such patient should always undergo a psychosexual assessment to prevent such incident in the future. These days sex toys are available in the market and can be utilized for sexual gratification.

\section{References}

[1] Van Ophoven, J. and Kernion, D.E. (2000) Clinical Management of Foreign Bodies of the Genitor-Urinary Tract. The Journal of Urology, 164, 274-287. http://dx.doi.org/10.1016/S0022-5347(05)67342-9

[2] Ooi, C.K., Goh, H.K., Chong, K.T. and Lim, G.H. (2009) Penile Strangulation: Report of Two Unusual Cases. Singapore Medical Journal, 50, e50-e52. 
[3] Okeke, L.I. (2008) Thread Embedded into Penile Tissue over Time as an Unusual Hair Thread Tourniquet Injury to the Penis: A Case Report. Journal of Medical Case Reports, 2, 230. http://dx.doi.org/10.1186/1752-1947-2-230

[4] Dar, N.R., Siddiqui, S., Qayyum, R. and Ghafoor, T. (2007) Hair Coil Strangulation-An Uncommon Cause of Penile Edema. Pediatric Dermatology, 24, E33-E35. http://dx.doi.org/10.1111/j.1525-1470.2007.00436.x

[5] Bhat, A.L., Saxena, G., Goyal, R. and Patni, M. (2001) A Rare Foreign Body on Penis Leading to Incarceration. International Urology and Nephrology, 32, 399-401. http://dx.doi.org/10.1023/A:1017565520257

[6] Bhat, A.L., Kumar, A., Mathur, S.C. and Ganwal, K.C. (1991) Penile Strangulation. British Journal of Urology, 68, 618-621. http://dx.doi.org/10.1111/j.1464-410X.1991.tb15426.X

[7] Jain, S., Gupta, A., Singh, T., Aggarwal, N., Sharma, S. and Jain, S. (2004) Penile Strangulation by a Hard Plastic Bottle: A Case Report. Indian Journal of Surgery, 66, 173-175.

[8] Kobayashi, H., Kaneko, G., Nishimoto, K. and Uchida, A. (2010) A Case of Penile Strangulation by Polyethylene Terephthalate Bottle. Acta Urologica Japonica, 56, 63-65.

[9] Voegeli, T.A. and Effert, P.J. (2005) Pentaethylene-Terephthalate (PET) Bottles: A New Device for Autoerotic Strangulation of the Penis Causing Serious Injury. Archives of Sexual Behavior, 34, 469-470. http://dx.doi.org/10.1007/s10508-005-4346-5

[10] Joshi, P., Patwardhan, P., Gadgil, D. and Kulkarni, H. (2009) Engorgement of Penis by Encircling Objects-An Emergency. The Internet Journal of Surgery, 24, 1.

[11] Rich, A. and Keating, M.A. (1999) Hair Tourniquet Syndrome of Clitoris. Journal of Urology, 162, 190. http://dx.doi.org/10.1097/00005392-199907000-00067

[12] Singh, R. and Singh, A. (2006) Penile Strangulation by Multiple Metallic Rings, Its Treatment and Use of Hand Doppler. The Internet Journal of Urology, $\mathbf{5}$.

[13] McGraw, J.B., Myers, B. and Shanklin, K.D. (1977) The Value of Fluorescein in Predicting the Viability of Arterial Flaps. Plastic and Reconstructive Surgery, 60, 710-719. http://dx.doi.org/10.1097/00006534-197711000-00006

[14] Silberstein, J., Grabowski, J., Lakin, C. and Goldstein, I. (2008) Penile Constriction Devices: Case Report, Review of the Literature, and Recommendations for Extrication. The Journal of Sexual Medicine, 5, 1747-1757. http://dx.doi.org/10.1111/j.1743-6109.2008.00848.x

[15] Banyra, D., Sheremeta, R. and Shulyak, A. (2013) Strangulation of Penis: Two Case Reports. Central European Journal of Urology, 66, 242-245.

[16] Kafka, M.P. and Hennen, J. (2003) Hypersexual Desire in Males: Are Males with Paraphilias Different from Males with Paraphilia-Related Disorders? Sexual Abuse, 15, 307-321. http://dx.doi.org/10.1177/107906320301500407 